\title{
Detecting Learning Strategies with Analytics: Links with Self-Reported Measures and Academic Performance
}

\author{
Dragan Gašević \\ The University of Edinburgh, United Kingdom \\ dgasevic@acm.org \\ Jelena Jovanović \\ University of Belgrade, Serbia \\ Abelardo Pardo \\ The University of Sydney, Australia \\ Shane Dawson \\ University of South Australia, Australia
}

\begin{abstract}
The use of analytic methods for extracting learning strategies from trace data has attracted considerable attention in the literature. However, there is a paucity of research examining any association between learning strategies extracted from trace data and responses to well-established self-report instruments and performance scores. This paper focuses on the link between the learning strategies identified in the trace data and student reported approaches to learning. The paper reports on the findings of a study conducted in the scope of an undergraduate engineering course $(\mathrm{N}=144)$ that followed a flipped classroom design. The study found that learning strategies extracted from trace data can be interpreted in terms of deep and surface approaches to learning. The detected significant links with self-report measures are with small effect sizes for both the overall deep approach to learning scale and the deep strategy scale. However, there was no observed significance linking the surface approach to learning and surface strategy nor were there significant associations with motivation scales of approaches to learning. The significant effects on academic performance were found, and consistent with the literature that used self-report instruments showing that students who followed a deep approach to learning had a significantly higher performance.
\end{abstract}

Keywords: Learning analytics, learning strategy, approaches to learning, self-reported measures

\section{INTRODUCTION}

The field of learning analytics evolved from the increased opportunities to collect and make use of data about learning and learning contexts (known as trace or log data) (Gašević, Dawson, \& Siemens, 2015). Although the field is driven by two underlying principles - to understand and to optimize learning and learning environments in which learning occurs - very little research to date has acutely addressed them (Siemens \& Gasevic, 2012). In early days of learning analytics, much attention was dedicated to the prediction of learning success. This was primarily motivated by the easy access to data that could be ISSN 1929-7750 (online). The Journal of Learning Analytics works under a Creative Commons License, Attribution - NonCommercial-NoDerivs 3.0 Unported (CC BY-NC-ND 3.0) 
(2017). Detecting learning strategies with analytics: Links with self-reported measures and academic performance. Journal of Learning Analytics, 4(2), 113-128. http://dx.doi.org/10.18608/jla.2017.42.10

used for predictive modelling and interest in both optimizing institutional processes and in increasing educational and monetary benefits for learners and educational providers (Colvin et al., 2015). Recent research in learning analytics however recognizes the significance of building upon educational theory in order to enable the use of advance machine learning methods to model behavioural, cognitive, and social processes associated with learning (Dawson, Drachsler, Rosé, Gašević, \& Lynch, 2016).

\section{$1.1 \quad$ Learning Analytics and Learning Theory}

Several authors have recently argued that in order to advance research and practice in learning analytics there is a critical need to connect and deepen such analytics with learning theory (Gašević, Dawson, Rogers, \& Gašević, 2016; Lodge \& Lewis, 2012; Rogers, Gašević, \& Dawson, 2016; Wise, 2014; Wise \& Shaffer, 2015). For example, Gašević, Dawson, Rogers, and Gašević (2016) suggest "a theoretically driven approach [that] leads to an ontologically deep engagement with intentions and causes, and the validation of models of learning, learning contexts, and learner behavior" (p. 70). Furthermore, Gašević et al. empirically show that instructional conditions need to be accounted for when examining the association between digital trace data and learning outcomes in order to make actionable insights into student learning progress. The importance of theory has also been explored in other studies such as the use of theory-informed mechanisms to develop learning analytics that support teacher regulation of collaborative groups (van Leeuwen, 2015), and examination of the use of effective study practices such as spacing effect (Miyamoto et al., 2015) and revisiting previously studied resources (Svihla, Wester, \& Linn, 2015).

The use of existing theory offers many benefits related to opportunities to improve study designs, inform selection of relevant variables and hypotheses formulation, enhance interpretation of the study findings, facilitate comparisons of the results with respect to already published findings, and enable replication of previous studies (Gašević et al., 2015; Wise \& Shaffer, 2015). A common recommendation is that studies involving the use of digital traces and learning analytics methods should start from an existing theory to inform their research questions and operationalize the measurements, and thus establish the use of trace data as valid proxies of constructs under study. This approach is already gaining much traction in the field of learning analytics and can be used as an effective way to study different complex concepts such as motivation (Zhou \& Winne, 2012) and study strategy (Lust, Elen, \& Clarebout, 2013b).

\subsection{Self-Reported Measures and Learning Analytics}

Although recent literature demonstrates some promising results stemming from the connection of learning theory with learning analytics, some tensions need to be further investigated. The conventional research in the learning sciences makes extensive use of self-report instruments. According to Azevedo (2015), self-reports, in addition to classroom discourse, are the only proven approach that can be used for the measurement of cognitive, metacognitive, affective, and motivational constructs of student engagement. This provides the rationale for making use of existing self-report instruments to interpret 
(2017). Detecting learning strategies with analytics: Links with self-reported measures and academic performance. Journal of Learning Analytics, 4(2), 113-128. http://dx.doi.org/10.18608/jla.2017.42.10

and triangulate findings obtained through the use of trace data (Beheshitha, Hatala, Gašević, \& Joksimović, 2016; Lust et al., 2013b).

Associations between trace and self-reported data on the same construct are not consistently observed. For example, Winne and Jamieson-Noel (2002) showed that learners are inaccurate in calibrating their self-reported and actual measures of the use of specific study tactics. Their study demonstrated that learners have a tendency to overestimate the use of specific study tactics. According to Zhou and Winne (2012) this inaccuracy in self-reports is likely due to poor learner reflection. As the authors stated, "...accounts may be based, in part, on biased information arising from incomplete and reconstructed memories plus subjective and implicit theories of the mental processes involved" (p. 414). Moreover, the Zhou and Winne (2012) study showed that trace data-based measures of student achievement goal orientation had much stronger associations with learning outcomes than self-reported ones. The authors interpret this finding as the difference between perceived intention and actual behaviour. The self-reported data measured student intentions while trace data measured realized intentions and allowed for collection of finer grain data points that were more proximal to the actual learning experiences. Thus, trace data had lower bias than that arising "from incomplete and reconstructed memories" (Zhou \& Winne, 2012, p. 414).

Combined use of trace data and self-reported measures is a new avenue of research recently reported in the literature. Pardo, Ellis, and Calvo (2015) explored how the conclusions derived from quantitative data derived from digital traces and self-reported qualitative data can be related. They concluded that the combined approach may lead to changes in learning designs not previously considered when only using one of the two data sources. In another study, Pardo, Han, and Ellis (2016) explored statistical models that combine self-reported measures of self-regulation, and digital traces extracted from the logs recorded by an online platform. Both studies point to the need to expand conventional analysis techniques to combine self-reported data sources with those derived from trace data recorded by online learning platforms.

\subsection{Learning Analytics and Learning Strategy}

The study reported in this paper looks at student learning strategies, opportunities for their measurement with trace data, associations with existing self-reported instruments of relevance, and effects of study strategies on learning outcomes. According to Weinstein, Husman, and Dierking (2000, p. 227) a learning strategy includes "any thoughts, behaviors, beliefs or emotions that facilitate the acquisition, understanding or later transfer of new knowledge and skills." Making effective choices and adaptation of learning strategies in response to the emerging needs from the learning environment are critical features of effective self-regulated learning. Such features are especially important in technology-enhanced environments where a high degree of self-regulated learning is necessary for learning success. However, existing research indicates that learners 1 ) tend to use ineffective learning strategies (Winne \& Jamieson-Noel, 2003), and 2) do not make effective use of available resources to 
(2017). Detecting learning strategies with analytics: Links with self-reported measures and academic performance. Journal of Learning Analytics, 4(2), 113-128. http://dx.doi.org/10.18608/jla.2017.42.10

optimize their learning even in the environments that build on effective learning designs (Ellis, Marcus, \& Taylor, 2005; Lust, Elen, \& Clarebout, 2013a).

A common approach to identifying learning strategies in learning analytics uses unsupervised methods for the analysis of trace data that capture activities of learners of relevance for learning designs in different contexts. Generally, studies have identified three to six learning strategies evolving from student use of online resources (Del Valle \& Duffy, 2009; Kovanović, Gašević, Joksimović, Hatala, \& Adesope, 2015; Lust et al., 2013a; Wise, Speer, Marbouti, \& Hsiao, 2013). For example, Lust, Vandewaetere, Ceulemans, Elen, and Clarebout (2011) reported three strategies found to be used by undergraduate educational sciences students in a blended course. These strategies included 1) no-users, who had very limited use of the online resources and did not use any of the provided face-to-face tools, 2) intensive users who regularly made use of the tools provided in the course design, and 3) incoherent users who only used online tools and did not engage with any of the face-to-face tools provided in the course design. Moreover, several studies also report significant associations between learning strategies, derived from trace data, and learning outcomes. For example, Lust et al. (2013b) reported that the adopted learning strategy had a significant moderate effect on student academic performance in an undergraduate educational sciences blended learning course. Kovanović et al. (2015) showed that learning strategy had a significant and large effect on the quality of knowledge construction evolving from online discussions in a fully online software engineering master's course.

Learning strategies reported in these studies are typically interpreted with respect to established theories such as approaches to learning (Trigwell \& Prosser, 1991), goal orientations (Elliot \& McGregor, 2001), and self-efficacy (Zimmerman, 2000). However, the majority of studies collected only the trace data related to the constructs of these theories. In contrast to this trend, Lust et al. (2013b) collected both trace data and self-reports about achievement goal orientations and self-efficacy. Self-reported data were then used to identify associations with strategies identified from trace data, and thus offer interpretations of the identified strategies.

\subsection{Research Aim}

The study reported in this paper examines the association between student approaches to learning (Biggs, 1987) and study strategies extracted from digital trace data about learner interactions with online learning resources. Approaches to learning are well-studied in the educational literature and offer a wealth of insights that can inform educational practice and research. Approaches to learning are referred to as either deep or surface. Deep learning reflects an ideal of modern education and is indicative of conceptual change. In contrast surface learning is typically associated with rote learning and memorization. Several studies indicate that students with high tendency towards deep approaches to learning have significantly higher academic performance than students with a high inclination towards surface approaches (Bliuc, Ellis, Goodyear, \& Piggott, 2010; Ellis, Goodyear, Calvo, \& Prosser, 2008). Trigwell, Prosser, and Waterhouse (1999) also identified an association between instructor conceptions of teaching and student approaches to learning. That is, students, in classes taught by 
(2017). Detecting learning strategies with analytics: Links with self-reported measures and academic performance. Journal of Learning Analytics, 4(2), 113-128. http://dx.doi.org/10.18608/jla.2017.42.10

instructors whose conception of teaching was conceptual change had a higher tendency towards a deep approach to learning. Conversely, students with a high tendency towards a surface approach to learning were more frequently observed in classes taught by instructors whose conception of teaching was knowledge transmission.

The literature that conceptualizes approaches to learning connects the roles of motivation and strategy to promote deep learning. This is best reflected in the well-known self-report instrument used for the measurement of approaches to learning, which has four main subscales: deep motive (DM), deep strategy (DS), surface motive (SM), and surface strategy (SS), whereby DM and DS measure deep approaches to learning, while SM and SS measure surface approaches to learning (Biggs, Kember, \& Leung, 2001). This conceptualization, composed of motivation and strategy components, makes approaches to learning suitable for the study of the association between self-reported approaches and the strategies identified from trace data.

Specifically, this study looks at the following research questions:

RQ1. Can we identify groups of learners based on learning strategies extracted from trace data? If so, can the identified groups be attributed to student approaches to learning? In other words, can the groups mined from student learning actions be explained by student approaches to learning?

RQ2. Are there significant differences between the identified student groups with respect to selfreported measures of approaches to learning?

RQ3. Are there significant differences between students with deep and surface approaches to learning extracted from trace data with respect to academic achievement?

\section{METHODS}

\subsection{Study Context}

The context of the study was a first-year engineering course in computer systems at an Australian research-intensive higher education institution. The course lasted 13 weeks and enrolled 290 students (81.5\% male, 18.5\% female). The flipped learning (FL) strategy of the course consisted of two key elements (Pardo \& Mirriahi, in press): 1) a set of preparatory learning activities to be completed prior to the face-to-face session with the instructor (i.e., the lecture); and 2) a redesigned lecture framed as an active learning session requiring student preparation and participation in collaborative problem solving tasks.

The study focused on the lecture preparation activities. These activities were considered essential for enabling students to participate effectively in the face-to-face sessions and therefore were crucial for the overall success of the FL design. Specifically, the preparation activities included 1) short videos that introduced and explained relevant course concepts, 2) multiple-choice questions (MCQs) that followed 
(2017). Detecting learning strategies with analytics: Links with self-reported measures and academic performance. Journal of Learning Analytics, 4(2), 113-128. http://dx.doi.org/10.18608/jla.2017.42.10

each video and covered the concepts discussed in the video; they were offered as formative assessment promoting simple factual recall; 3 ) reading materials with embedded MCQs; these questions were conceptualized in the same way and served the same formative role as MCQs accompanying course videos; 4) problem (exercise) sequences that served as summative assessment. While working on these activities, students had access to an analytics dashboard offering them real-time feedback on their engagement level and activity scores (Khan \& Pardo, 2016). The dashboard was updated every 15 minutes, and the magnitudes were reset each week.

\subsection{Data Sources and Variables}

The study incorporated three data sources. The first was the Study Process Questionnaire (SPQ) aimed at assessing student approaches to learning in a given learning context (Biggs et al., 2001). Since it was administered at the beginning of the course, it provided insight into the extent to which student learning approaches differed in the given teaching context. The questionnaire contained 20 questions with answers based on a seven-point Likert scale (from strongly disagree to strongly agree). The questions were organized into four groups measuring the following four constructs: deep motive (DM), deep strategy (DS), surface motive (SM), and surface strategy (SS). To compute values of the variables corresponding to these constructs, we averaged answers to the questions related to each construct. In addition, as suggested by Biggs et al. (2001), the Deep Approach (DA) variable was computed by averaging the values of DM and DS variables, whereas the Surface Approach (SA) variable was calculated as the average of the SM and SS variables. The SPQ-based variables were essential for addressing our research questions. However, a proportion of enrolled students $\left(\mathrm{N}_{\text {no-survey }}=146\right)$ did not complete the SPQ questionnaire. As such the analyses were only based on the data related to the students who did complete the questionnaire $\left(\mathrm{N}_{\text {survey }}=144\right)$.

The second data source included trace data related to the students' preparatory learning activities during the active period of the 2014 delivery of the course (weeks 2-13). These data were collected from the Learning Management System (LMS) used in the course. Learning sessions were extracted from the trace data as logs of continuous sequences of events where any two consecutive events were within 30 minutes of one another (Khan \& Pardo, 2016). This resulted in 6,196 learning sessions for the 144 students (who filled in SPQ) and the 12 active weeks of the course. These learning sessions were encoded as sequences of learning actions, based on the sequence representation format of the TraMineR R package (Gabadinho, Ritschard, Mueller, \& Studer, 2011) that was used for the exploration and subsequent clustering of the learning sequence. Examples of actions that form learning sequences included formative assessment done correctly, formative assessment done incorrectly, asking to see the solution for a formative assessment item, watching a course video, accessing a page with the course reading content, and the like.

The LMS also served as the data source for student assessment results (scores on the midterm and final exams). The midterm and final exam scores are numerical variables with values in the range [0-20] and [0-40] respectively. 
(2017). Detecting learning strategies with analytics: Links with self-reported measures and academic performance. Journal of Learning Analytics, 4(2), 113-128. http://dx.doi.org/10.18608/jla.2017.42.10

\subsection{Data Analysis}

Clustering was used for grouping similar learning sequences $(N=6,196)$ to detect patterns in student learning behaviour (i.e., adopted learning strategies), and subsequently for grouping students ( $N=144)$ based on the identified sequence patterns (i.e., learning strategies). In both cases, we used agglomerative hierarchical clustering, based on Ward's algorithm. This clustering technique was suggested as particularly suitable for detecting student groups in online learning contexts (Kovanović et al., 2015).

Learning sequences were clustered based on their similarity computed using the optimal matching method. Being a variant of the Levenshtein's (1966) edit distance metric, this method computes distance between any two learning sequences as the minimal cost, in terms of insertions, deletions and/or substitutions of learning actions, required for transforming one sequence into another (Gabadinho et al., 2011).

Clustering of students was based on the output of the sequence clustering. In particular, features used for student clustering included 1) four variables, seq.clust $t_{i}, i=1: 4$, where seq.clust $t_{i}$ is the number of learning sequences in sequence cluster $i$ for a particular student, and 2) seq.total feature representing the total number of learning sequences per student.

Following the conceptualization of Biggs and colleagues (2001) of learning approaches, the identified student clusters were categorized into two groups reflective of deep and surface approaches to learning. To compare these two groups with respect to the SPQ variables (DM, DS, SM, SS, DA, and SA), Mann Whitney $U$ test was used, as the variables did not meet the homogeneity of variances assumption required for parametric tests. The same test was used for the comparison of the two groups with respect to the midterm and final exam scores (these variables were not normally distributed). Cohen's $d$ metric was used for assessing the effect size. Significance level was set at alpha=0.05.

\section{$3 \quad$ RESULTS}

\subsection{RQ1: Student Groups with Shared Patterns in Learning Behaviour}

The cluster analyses of the extracted learning sequences $(N=6,196)$ led to the following four cluster solution:

1. Focus on formative assessment. Sequences following this pattern ( $N=792 ; 12.78 \%$ of the total number of extracted sequences) are characterized by the dominance of activities related to formative assessment, and almost complete absence of summative assessment. Interaction with the course reading materials is slightly present, and tends to be more prominent at the beginning of the learning sessions. Metacognitive evaluation activities (i.e., access to the dashboard) tend to occur towards the end of these learning sessions. 
(2017). Detecting learning strategies with analytics: Links with self-reported measures and academic performance. Journal of Learning Analytics, 4(2), 113-128. http://dx.doi.org/10.18608/jla.2017.42.10

2. Summative assessment through trial and error. This pattern is the most prominent one $(\mathrm{N}=2,488$; $40.15 \%$ of all the extracted sequences) with sequences largely dominated by summative assessment activities that more frequently result in incorrect than in correct solutions.

3. Studying reading materials. Sequences sharing this pattern $(N=1,891 ; 30.52 \%)$ mainly consist of interactions with the class reading materials and a tiny fraction of formative assessment activities. These sequences tend to be shorter, and end with watching the course videos.

4. Video watching coupled with (mostly formative) assessment. Sequences in this group ( $N=1,025$; $16.65 \%$ ) are characterized by the large presence of video watching activities. A considerable number of formative assessment activities are gradually, towards the end of the sessions, substituted by summative assessment. Another specificity of this pattern is the presence of metacognitive activities at the beginning of the sessions.

Clustering of students based on the identified clusters of learning sequences led to the solution with four student clusters as the best one. Table 1 describes the obtained student clusters by providing basic descriptive statistics (median, $25^{\text {th }}$, and $75^{\text {th }}$ percentiles) for the five variables used for clustering (number of student learning sequences in each of the four sequence clusters, and the total number of student sequences). The table also gives descriptive statistics for the group (i.e., cluster) scores on the midterm exam and the final exam.

Table 1: Summary Statistics for the Four Student Clusters: Median, $25^{\text {th }}$, and $75^{\text {th }}$ Percentiles

\begin{tabular}{lcccc}
\hline & \multicolumn{4}{c}{ Student clusters } \\
& 1 & 2 & 3 & 4 \\
& $(\mathrm{~N}=17 ; 11.80 \%)$ & $(\mathrm{N}=38 ; 26.39 \%)$ & $(\mathrm{N}=48 ; 33.33 \%)$ & $(\mathrm{N}=41 ; 28.47 \%)$ \\
\hline Number of seq. in seq. cluster 1 & $16(12,21)$ & $5.5(3.25,8)$ & $4(3,6)$ & $1(0,2)$ \\
Number of seq. in seq. cluster 2 & $21(19,23)$ & $19(17,22)$ & $17(14,20)$ & $14(11,17)$ \\
Number of seq. in seq. cluster 3 & $32(25,37)$ & $18(14,20)$ & $10(8,12)$ & $5(3,6)$ \\
Number of seq. in seq. cluster 4 & $10(9,16)$ & $11(9,14)$ & $5(3,7.25)$ & $2(1,4)$ \\
Total number of sequences & $76(74,87)$ & $54.5(49.25,59)$ & $36(33,41.25)$ & $23(19,26)$ \\
Midterm exam score & $16(13,17)$ & $16(13.25,17)$ & $14(11,16)$ & $11(10,15)$ \\
Final exam score & $26(19,32)$ & $27.5(15.25,31)$ & $17(12.75,23.5)$ & $15(11,21)$ \\
\hline
\end{tabular}

According to Biggs et al. (2001), students can be differentiated based on their approaches to learning: the deep approach is characterized by critical evaluation and syntheses of information, and driven by intrinsic motivation, whereas the surface approach is dominated by shallow cognitive strategies and is associated with extrinsic motivation. Students from the first two clusters presented in Table 1 can be characterized as having a deep approach to learning, since they were actively engaged with the course (especially students from cluster 1 ), and practiced a variety of learning strategies, obviously trying to adapt to the course requirements. The fact that these students had high exam performance indicates ISSN 1929-7750 (online). The Journal of Learning Analytics works under a Creative Commons License, Attribution - NonCommercial-NoDerivs 3.0 Unported (CC BY-NC-ND 3.0) 
(2017). Detecting learning strategies with analytics: Links with self-reported measures and academic performance. Journal of Learning Analytics, 4(2), 113-128. http://dx.doi.org/10.18608/jla.2017.42.10

that they tend to be successful in adapting/regulating their learning. Moreover, they were more engaged in the strategies proven to be effective in promoting learning than in those recognized as passive. For example, engagement into the formative assessment opportunities can be interpreted as the use of self-testing study tactics that have proven to be one of the effective desirable difficulties in learning (Bjork \& Bjork, 2011). Reading and video watching, on the other hand, are typically reported in the literature as ineffective study strategies.

Students from clusters 3 and 4 can be categorized as following a surface approach in the context of the examined course. In the case of cluster 4, the surface approach to learning is evident in the students' low engagement levels. Students from cluster 3 can be characterized as selective, performanceoriented, and aimed at achieving high scores through minimal engagement (evident in their primary focus on summative assessment - strategy 2). While in some cases this performance-oriented approach might lead to good exam performance, it was not the case in this study. This finding suggests that the ability of these students to regulate their learning was less than optimal. This finding is further supported by the fact that when not engaged in summative assessment, students from cluster 3 preferred the reading strategy (strategy 3 ) over the two more effective learning strategies presented through formative assessment (strategies 1 and 4). Finally, students from clusters 3 and 4 had a comparatively lower number of learning sequences in comparison to students from clusters 1 and 2; this suggests a lower level of motivation.

\subsection{RQ2: Comparison of Observed and Perceived Approaches to Learning}

To examine the level of correspondence between student approaches to learning identified through the analysis of their learning sequences and their learning approaches estimated through SPQ, we first grouped the students from clusters 1 and 2 into the deep approach group, and clusters 3 and 4 into the surface approach group. Next, we compared the two groups based on the 6 variables derived from the student answers to the SPQ questionnaire (Table 2). Mann Whitney $U$ tests showed statistically significant differences between the two groups for the Deep Strategy (DS) and Deep Approach (DA) variables. In particular, students from the deep approach group had significantly higher scores on the DS scale than students from the surface approach group: $Z=2.7206, p=0.006, d=0.2267$. Likewise, the deep approach group had significantly higher scores on the DA scale than the surface approach group: $Z=2.2106, p=0.027, d=0.1842$.

\subsection{RQ3: Academic Achievement of the Observed Deep and Surface Approach Groups}

To examine the observed deep and surface approach groups from the perspective of their academic achievement, we compared the scores of the two groups on the midterm exam and the final exam (Table 2, the last two rows). Mann Whitney $U$ tests confirmed that compared to the surface approach group (student clusters 3 and 4, Table 1), the deep approach group (student clusters 1 and 2) had 
(2017). Detecting learning strategies with analytics: Links with self-reported measures and academic performance. Journal of Learning Analytics, 4(2), 113-128. http://dx.doi.org/10.18608/jla.2017.42.10

significantly higher midterm exam scores $(Z=4.3133, p<0.0001, d=0.3594)$ and final exam scores $(Z=4.5136, p<0.0001, d=0.3761)$.

Table 2: Summary statistics for the 6 SPQ-based variables and exam scores (median, $25^{\text {th }}$, and $75^{\text {th }}$ percentiles)

\begin{tabular}{lcc}
\hline Variables & Deep Approach group & Surface Approach group \\
\hline Deep Strategy (DS) & $5.0(4.0,5.4)$ & $4.4(4.0,4.8)$ \\
Surface Strategy (SS) & $3.6(2.8,4.4)$ & $4.0(3.2,4.6)$ \\
Deep Motive (DM) & $4.6(3.8,5.3)$ & $4.4(3.8,5.0)$ \\
Surface Motive (SM) & $3.0(2.2,3.8)$ & $3.0(2.6,3.8)$ \\
Deep Approach (DA) & $4.7(4.0,5.25)$ & $4.4(3.9,4.8)$ \\
Surface Approach (SA) & $3.4(2.55,4.05)$ & $3.5(2.9,4.2)$ \\
Midterm exam score & $16(13,17)$ & $13(11,16)$ \\
Final exam score & $27(17,31.5)$ & $16(12,21)$ \\
\hline
\end{tabular}

\section{DISCUSSION}

In addressing the first research question (RQ1), the study found four clusters of students with respect to their learning strategy as extracted from the trace data. Two of those clusters ( 1 and 2 ) corresponded to a deep approach to learning, while the remaining two ( 3 and 4 ) corresponded to a surface approach to learning. The clusters that corresponded to a deep approach showed a higher overall amount of activity compared to the clusters interpreted as having a surface approach to learning. The students in deep approach clusters also exhibited a good balance between the use of different strategies, effectively combining strategies proven to promote learning (i.e., formative assessment as a manifestation of the self-testing desirable difficulty) with those that are less potent (i.e., reading and video watching), as well as those that are more performance-oriented (i.e., strategy focused on summative assessment through trial and error). According to Entwistle (2009), a deep approach to learning typically involves a combined use of both deep and surface strategies to learning. Likewise, the literature on achievement goal orientation indicates that some elements of performance goal orientation are necessary for learners to better regulate their learning in order to meet the external standards set by the course design (Elliot \& McGregor, 2001). Alternatively, the clusters of students characterized as those who followed a surface approach to learning predominantly followed a performance oriented strategy (i.e., summative assessment through trial and error) and demonstrated a lower overall amount of activity (i.e., likely lower motivation) than their peers engaged in a deep approach.

The extraction of trace data to establish deep and surface approaches to learning complements the selfreport instrument designed by Biggs and colleagues (2001) to measure a student's "approach to learning." Research question two (RQ2) was designed to further probe this assumption and test whether indeed there were significant differences between the groups extracted from trace data with respect to their responses to Biggs and colleagues' self-report instrument. The results showed a significant 
(2017). Detecting learning strategies with analytics: Links with self-reported measures and academic performance. Journal of Learning Analytics, 4(2), 113-128. http://dx.doi.org/10.18608/jla.2017.42.10

difference between the groups for the overall self-reported deep approach (DA) scores and the selfreported deep strategy (DS) scores. However, no significant differences were detected with respect to either of the two motivation scales (DM and SM) or with regards to surface approach (SA) and surface strategy (SS). The lack of difference on the surface strategy may be attributed to the already mentioned links to Entwistle's (2009) position about the combination of deep and surface strategies in the deep approach to learning, and Elliot \& McGregor's (2001) interpretation of performance orientation. This interpretation needs to be tested in future studies, especially as the effect sizes were small (Cohen's $d$ was just around 0.2).

The lack of differences between the clusters extracted from the trace data on both motivational scales of the self-reported instrument is less clear. Given that the instrument was administered at the beginning of the course, it only represented student motivation intention at a single point in time. However, literature on student motivation indicates that the largest proportion of variability in motivation and engagement is explained by within-day changes (23\%) and between students (67\%) (Martin et al., 2015). Similarly, Zhou and Winne (2012) demonstrated that real-time measurement of achievement goal orientation that was temporally proximal to the completion of actual learning activities had a much stronger association with learning outcomes than self-reported measures of achievement goal orientation administered at the start of the learning session. Zhou and Winne (2012) attributed this to the fact that self-reported measures represented only student intention, while real time measures of goal orientation represented realized motivation intentions. Therefore, we can conclude that further research is required to understand the ways that real-time measurement of learning motivation in general and motivation in connection to approaches to learning in particular can be achieved, so that advanced insights into approaches to learning based on trace data can be obtained.

The comparison of the deep and surface approach groups extracted from trace data revealed significant differences in the performance scores on both mid-term and final exams of the course examined in the study. This finding might have been affected by student prior knowledge of the course topics; however, as the data related to this potentially confounding variable were not available, we were not able to control for it. Still, this finding is consistent with the previous literature based on self-reports and shows that students who follow a deep approach to learning have higher academic performance (Bliuc et al., 2010; Ellis et al., 2008). This can inform teaching practice and be used as a foundation for a learning analytics tool for teachers to help them gain deeper insights into a student's approach to learning as revealed by the trace data. In essence, instructors could derive specific recommendations for their students with respect to the strategies they need to follow and corrective measures they can take to optimize their students' approaches to learning. This implication on teaching practice is contingent on the conceptions teachers may have and assumes that their conceptions of teaching are in alignment with a deep approach to learning (Trigwell et al., 1999). A direct impact of teacher conceptualizations and student trace data is the embedding of more elaborate learning designs resulting in the effective use of technology that promotes conceptual change. However, achievement of this impact also implies that instructors are cognizant of how their teaching practice can encourage either a deep or surface 
(2017). Detecting learning strategies with analytics: Links with self-reported measures and academic performance. Journal of Learning Analytics, 4(2), 113-128. http://dx.doi.org/10.18608/jla.2017.42.10

approach to learning. Recent adoption of teaching practices that promote flipped classroom designs (O'Flaherty, Phillips, Karanicolas, Snelling, \& Winning, 2015) and active learning (Freeman et al., 2014) are encouraging directions for this change to happen.

This study is likely susceptible to the self-selection bias as it included only those students who completed the optional self-report instrument. Based on that, it can be argued that those students who completed the instruments were more motivated to complete the course and thus likely more engaged. To check for the impact of self-selection bias, we compared the students included in this study and others who did not complete the self-report survey on several variables (see Table 3 ). The comparison showed that students included in the study had significantly higher scores on the final exam $(Z=-2.883$, $p=0.0038, d=0.1693$ ) and a significantly higher total number of sequences used as indicators of overall engagement level $(Z=-3.2505, p=0.001, d=0.1909)$. Midterm exam scores did not differ significantly between the two groups. We also identified a significant association between a variable indicating if a student responded to the questionnaire and the cluster the student was assigned to (when clustering was done with all 290 students), $\chi^{2}=13.828, p=0.003$. Examining this further, using logistic regression, we found that the odds of responding to the questionnaire were higher for students pursuing deep learning approach (clusters 1 and 2) than for students following a surface approach (clusters 3 and 4). These findings indeed confirm the self-selection bias and warrant future, more inclusive studies. Due to the optional nature of self-report instruments, this task can be a conundrum to be addressed with conventional self-reported approaches. The use of previously mentioned real-time measures, in addition to the benefits related to the validity of the measurement process, could also address the self-selection bias and increase inclusiveness of future studies.

Table 3: Comparisons of students who completed the SPQ and those who did not

\begin{tabular}{lcc}
\hline & $\begin{array}{c}\text { Group who completed } \\
\text { the SPQ }(\mathrm{N}=144)\end{array}$ & $\begin{array}{c}\text { Group who did not complete } \\
\text { the SPQ }(\mathrm{N}=146)\end{array}$ \\
\hline Midterm exam & $14(11,17)$ & $13(10.25,16)$ \\
Final exam & $19(14,28)$ & $16(12,22)$ \\
Total number of learning sequences & $39(29,55)$ & $32.5(21,45.75)$ \\
\hline
\end{tabular}

\section{CONCLUSION}

While the research in learning analytics is rapidly growing, and increasing in depth and diversity, there remains much work in addressing the field's primary goals of both understanding and optimizing student learning. The study findings further illustrate that student self-report instruments largely measure intentions to study in lieu of realized intentions. In this context, the deficiencies associated with interpreting trace data are also reflected in the self-report instruments. That is, while clicks of activity sequences provide specific granular detail about a student's realized intentions, there remains a gap in connecting how these traces of digital behaviour relate to the learning process. Similarly, the self-report 
(2017). Detecting learning strategies with analytics: Links with self-reported measures and academic performance. Journal of Learning Analytics, 4(2), 113-128. http://dx.doi.org/10.18608/jla.2017.42.10

instruments provide insight into a student's future intentions for study and hence are yet to be actualized and evidenced. Clearly, there is further work to undertake in merging these approaches to measuring learning. Such multi-faceted approaches have the potential to yield more productive insights into student learning and the learning context.

\section{REFERENCES}

Azevedo, R. (2015). Defining and measuring engagement and learning in science: Conceptual, theoretical, methodological, and analytical issues. Educational Psychologist, 50(1), 84-94. http://dx.doi.org/10.1080/00461520.2015.1004069

Beheshitha, S. S., Hatala, M., Gašević, D., \& Joksimović, S. (2016). The role of achievement goal orientations when studying effect of learning analytics visualizations. Proceedings of the $6^{\text {th }}$ International Conference on Learning Analytics and Knowledge (LAK 'LA), 25-29 April 2016, Edinburgh, UK (pp. 54-63). New York: ACM. http://dx.doi.org/10.1145/2883851.2883904

Biggs, J. (1987). Student approaches to learning and studying. (Research Monograph). Australian Council for Educational Research. Retrieved from http://eric.ed.gov/?id=ED308201

Biggs, J., Kember, D., \& Leung, D. Y. P. (2001). The revised two-factor Study Process Questionnaire: RSPQ-2F. British Journal of Educational Psychology, 71(1), 133-149. http://dx.doi.org/10.1348/000709901158433

Bjork, E. L., \& Bjork, R. A. (2011). Making things hard on yourself, but in a good way: Creating desirable difficulties to enhance learning. In M. A. Gernsbacher, R. W. Pew, L. M. Hough, \& J. R. Pomerantz (Eds.), Psychology and the real world: Essays illustrating fundamental contributions to society (pp. 56-64).

Bliuc, A.-M., Ellis, R. A., Goodyear, P., \& Piggott, L. (2010). Learning through face-to-face and online discussions: Associations between students' conceptions, approaches and academic performance in political science. British Journal of Educational Technology, 41(3), 512-524. http://dx.doi.org/10.1111/j.1467-8535.2009.00966.x

Colvin, C., Rogers, T., Wade, A., Dawson, S., Gašević, D., Buckingham Shum, S., ... Fisher, J. (2015). Student retention and learning analytics: A snapshot of Australian practices and a framework for advancement (Research Report). Canberra, Australia: Office of Learning and Teaching, Australian Government.

Dawson, S., Drachsler, H., Rosé, C. P., Gašević, D., \& Lynch, G. (Eds.). (2016). Proceedings of the $6^{\text {th }}$ International Conference on Learning Analytics and Knowledge (LAK '16), 25-29 April 2016, Edinburgh, UK. New York: ACM.

Del Valle, R., \& Duffy, T. M. (2009). Online learning: Learner characteristics and their approaches to managing learning. Instructional Science, 37(2), 129-149. http://dx.doi.org/10.1007/s11251007-9039-0

Elliot, A. J., \& McGregor, H. A. (2001). A 2 X 2 achievement goal framework. Journal of Personality and Social Psychology, 80, 501-519. 
(2017). Detecting learning strategies with analytics: Links with self-reported measures and academic performance. Journal of Learning Analytics, 4(2), 113-128. http://dx.doi.org/10.18608/jla.2017.42.10

Ellis, R. A., Goodyear, P., Calvo, R. A., \& Prosser, M. (2008). Engineering students' conceptions of and approaches to learning through discussions in face-to-face and online contexts. Learning and Instruction, 18(3), 267-282. http://dx.doi.org/10.1016/j.learninstruc.2007.06.001

Ellis, R. A., Marcus, G., \& Taylor, R. (2005). Learning through inquiry: Student difficulties with online course-based material. Journal of Computer Assisted Learning, 21(4), 239-252. http://dx.doi.org/10.1111/j.1365-2729.2005.00131.x

Entwistle, N. J. (2009). Teaching for understanding at university: Deep approaches and distinctive ways of thinking. Basingstoke, UK: Palgrave Macmillan.

Freeman, S., Eddy, S. L., McDonough, M., Smith, M. K., Okoroafor, N., Jordt, H., \& Wenderoth, M. P. (2014). Active learning increases student performance in science, engineering, and mathematics. Proceedings of the National Academy of Sciences, 111(23), 8410-8415, http://dx.doi.org/10.1073/pnas.1319030111

Gabadinho, A., Ritschard, G., Mueller, N. S., \& Studer, M. (2011). Analyzing and visualizing state sequences in $\mathrm{R}$ with TraMineR. Journal of Statistical Software, 40(4), 1-37. http://dx.doi.org/10.18637/jss.v040.i04

Gašević, D., Dawson, S., Rogers, T., \& Gašević, D. (2016). Learning analytics should not promote one size fits all: The effects of instructional conditions in predicting learning success. The Internet and Higher Education, 28, 68-84. http://dx.doi.org/10.1016/j.iheduc.2015.10.002

Gašević, D., Dawson, S., \& Siemens, G. (2015). Let's not forget: Learning analytics are about learning. TechTrends, 59(1), 64-71. http://dx.doi.org/10.1007/s11528-014-0822-x

Khan, I., \& Pardo, A. (2016). Data2U: Scalable real time student feedback in active learning environments. Proceedings of the $6^{\text {th }}$ International Conference on Learning Analytics and Knowledge (LAK 'LA), 25-29 April 2016, Edinburgh, UK (pp. 249-253). New York: ACM. http://dx.doi.org/10.1145/2883851.2883911

Kovanović, V., Gašević, D., Joksimović, S., Hatala, M., \& Adesope, O. (2015). Analytics of communities of inquiry: Effects of learning technology use on cognitive presence in asynchronous online discussions. The Internet and Higher Education, 27, 74-89. http://dx.doi.org/10.1016/j.iheduc.2015.06.002

Levenshtein, V. I. (1966). Binary codes capable of correcting deletions, insertions and reversals. Soviet Physics Doklady, 10, 707-710.

Lodge, J., \& Lewis, M. (2012). Pigeon pecks and mouse clicks: Putting the learning back into learning analytics. Proceedings of the $33^{\text {rd }}$ Annual Conference of the Australasian Society for Computers in Learning in Tertiary Education (ASCILITE 2016). 28-30 November 2016, Wellington, New Zealand (pp. 560-564). Australasian Society for Computers in Learning in Tertiary Education.

Lust, G., Elen, J., \& Clarebout, G. (2013a). Regulation of tool-use within a blended course: Student differences and performance effects. Computers \& Education, 60(1), 385-395. http://dx.doi.org/10.1016/j.compedu.2012.09.001

Lust, G., Elen, J., \& Clarebout, G. (2013b). Students' tool-use within a web enhanced course: Explanatory mechanisms of students' tool-use pattern. Computers in Human Behavior, 29(5), 2013-2021. http://dx.doi.org/10.1016/j.chb.2013.03.014 
(2017). Detecting learning strategies with analytics: Links with self-reported measures and academic performance. Journal of Learning Analytics, 4(2), 113-128. http://dx.doi.org/10.18608/jla.2017.42.10

Lust, G., Vandewaetere, M., Ceulemans, E., Elen, J., \& Clarebout, G. (2011). Tool-use in a blended undergraduate course: In Search of user profiles. Computers \& Education, 57(3), 2135-2144. http://dx.doi.org/10.1016/j.compedu.2011.05.010

Martin, A. J., Papworth, B., Ginns, P., Malmberg, L.-E., Collie, R. J., \& Calvo, R. A. (2015). Real-time motivation and engagement during a month at school: Every moment of every day for every student matters. Learning and Individual Differences, 38, 26-35. http://dx.doi.org/10.1016/j.lindif.2015.01.014

Miyamoto, Y. R., Coleman, C., Williams, J. J., Whitehill, J., Nesterko, S., \& Reich, J. (2015). Beyond timeon-task: The relationship between spaced study and certification in MOOCs. Journal of Learning Analytics, 2(2), 47-69. http://dx.doi.org/10.18608/jla.2015.22.5

O'Flaherty, J., Phillips, C., Karanicolas, S., Snelling, C., \& Winning, T. (2015). The use of flipped classrooms in higher education: A scoping review. The Internet and Higher Education, 25, 85-95. http://dx.doi.org/10.1016/j.iheduc.2015.02.002

Pardo, A., Ellis, R. A., \& Calvo, R. A. (2015). Combining observational and experiential data to inform the redesign of learning activities. Proceedings of the $5^{\text {th }}$ International Conference on Learning Analytics and Knowledge (LAK '(L), 16-20 March 2015, Poughkeepsie, NY, USA (pp. 305-309). New York: ACM. http://dx.doi.org/10.1145/2723576.2723625

Pardo, A., Han, F., \& Ellis, R. A. (2016). Exploring the relation between self-regulation, online activities, and academic performance: A case study. Proceedings of the $6^{\text {th }}$ International Conference on Learning Analytics and Knowledge (LAK 'LA), 25-29 April 2016, Edinburgh, UK (pp. 422-429). New York: ACM. http://dx.doi.org/10.1145/2883851.2883883

Pardo, A., \& Mirriahi, N. (in press). Design, deployment and evaluation of a flipped learning first year engineering course. In C. Reidsema, L. Kavanagh, R. Hadgraft, \& N. Smith (Eds.), Flipping the Classroom: Practice and Practices. Singapore: Springer.

Rogers, T., Gašević, D., \& Dawson, S. (2016). Learning analytics and the imperative for theory driven research. In C. Haythornthwaite, R. Andrews, J. Fransma, \& E. Meyers (Eds.), The SAGE Handbook of E-Learning Research, 2nd ed. (pp. 232-250). London, UK: SAGE Publications.

Siemens, G., \& Gasevic, D. (2012). Guest editorial: Learning and knowledge analytics. Educational Technology \& Society, 15(3), 1-2.

Svihla, V., Wester, M. J., \& Linn, M. C. (2015). Distributed revisiting: An analytic for retention of coherent science learning. Journal of Learning Analytics, 2(2), 75-101. http://dx.doi.org/10.18608/jla.2015.22.7

Trigwell, K., \& Prosser, M. (1991). Improving the quality of student learning: The influence of learning context and student approaches to learning on learning outcomes. Higher Education, 22(3), 251-266. http://dx.doi.org/10.1007/BF00132290

Trigwell, K., Prosser, M., \& Waterhouse, F. (1999). Relations between teachers' approaches to teaching and students' approaches to learning. Higher Education, 37(1), 57-70. http://dx.doi.org/10.1023/A:1003548313194 
(2017). Detecting learning strategies with analytics: Links with self-reported measures and academic performance. Journal of Learning Analytics, 4(2), 113-128. http://dx.doi.org/10.18608/jla.2017.42.10

van Leeuwen, A. (2015). Learning analytics to support teachers during synchronous CSCL: Balancing between overview and overload. Journal of Learning Analytics, 2(2), 138-162. http://dx.doi.org/10.18608/jla.2015.22.11

Weinstein, C. E., Husman, J., \& Dierking, D. R. (2000). Self-regulation interventions with a focus on learning strategies. In P. R. Pintrich \& M. Boekaerts (Eds.), Handbook on self-regulation (pp. 727747). New York: Academic Press.

Winne, P. H., \& Jamieson-Noel, D. (2002). Exploring students' calibration of self reports about study tactics and achievement. Contemporary Educational Psychology, 27(4), 551-572. http://dx.doi.org/10.1016/S0361-476x(02)00006-1

Winne, P. H., \& Jamieson-Noel, D. (2003). Self-regulating studying by objectives for learning: Students' reports compared to a model. Contemporary Educational Psychology, 28(3), 259-276. http://dx.doi.org/10.1016/S0361-476x(02)00041-3

Wise, A. F. (2014). Designing pedagogical interventions to support student use of learning analytics. Proceedings of the $4^{\text {th }}$ International Conference on Learning Analytics and Knowledge (LAK 'LA), 24-28 March 2014, Indianapolis, IN, USA (pp. 203-211). New York: ACM. http://dx.doi.org/10.1145/2567574.2567588

Wise, A. F., \& Shaffer, D. W. (2015). Why theory matters more than ever in the age of big data. Journal of Learning Analytics, 2(2), 5-13. http://dx.doi.org/10.18608/jla.2015.22.2

Wise, A. F., Speer, J., Marbouti, F., \& Hsiao, Y.-T. (2013). Broadening the notion of participation in online discussions: Examining patterns in learners' online listening behaviors. Instructional Science, 41(2), 323-343. http://dx.doi.org/10.1007/s11251-012-9230-9

Zhou, M., \& Winne, P. H. (2012). Modeling academic achievement by self-reported versus traced goal orientation. Learning and Instruction, 22(6), 413-419. http://dx.doi.org/10.1016/j.learninstruc.2012.03.004

Zimmerman, B. J. (2000). Self-efficacy: An essential motive to learn. Contemporary Educational Psychology, 25(1), 82-91. http://dx.doi.org/10.1006/ceps.1999.1016 